\title{
Applications of Decision Support System in Aviation Maintenance
}

\author{
Peng Zhang, Shi-Wei Zhao, Bin Tan, Li-Ming Yu and Ke-Qiang Hua \\ Civil Aviation University of China, Tianjin
}

China

\section{Introduction}

The basic purpose of aviation maintenance is to prevent the decreased levels of original aircraft airworthiness, safety and reliability design at the lowest cost, which is of great significance to the running of air transport enterprises. According to statistics, aviation maintenance accounts for approximately $20 \%$ to $30 \%$ of direct operating costs, not including indirect costs caused due to maintenance, such as flight delays, material and spare parts, corporate image.

In recent years, as the rapid development of civil aviation industry, a large number of new technologies have been used in airplanes, which increase the complexity of the civil aviation maintenance, especially the application of digital information technology. In response to modern aviation maintenance of the new situation, so as to adapt to the future development trend of digital maintenance and improve the efficiency and quality of modern aircraft maintenance, establishing the necessary modern air transport aircraft maintenance decision support system becomes increasingly urgent. For this reason, this paper in-depth analysis the problem of how to build the aviation Maintenance Decision Support System (MDSS).

\section{The components of aviation maintenance decision support system}

With modern communication technology, fault diagnosis technology and modern control technology, aviation maintenance decision support system can achieve real-time data exchange between air and ground, and it is able to provide effective decision support for rapid fault diagnosis and digital maintenance. This system should be composed of information acquisition and processing, aircraft maintenance support, material management, maintenance management, maintenance event evaluation, etc. As shown in Figure 1.

\subsection{Information acquisition and processing}

Aviation maintenance decision support system needs a variety of real-time data and historical data for decision support judgments, and all these data are collected by information acquisition and processing module.

\subsubsection{Real-time data acquisition and processing}

With the large number of information technology applied in civil aircraft, modern aircrafts are equipped with central maintenance computer, aircraft condition monitoring system and 
other real-time aircraft state parameters acquisition and monitor systems, which make it possible to monitor aircraft state parameters during the whole flight. Specifically, the collected aircraft state parameters are inputted to the aircraft online fault diagnosis system, which diagnoses the fault of aircraft by the established online fault diagnosis model. The result should be real-time transmitted to the ground system through the air-ground data link (such as Aircraft Communications Addressing and Reporting System(ACARS)), so as to provide decision support for ground maintenance and achieve rapid repair of aircraft failure, thus improving efficiency in the use of aircraft.

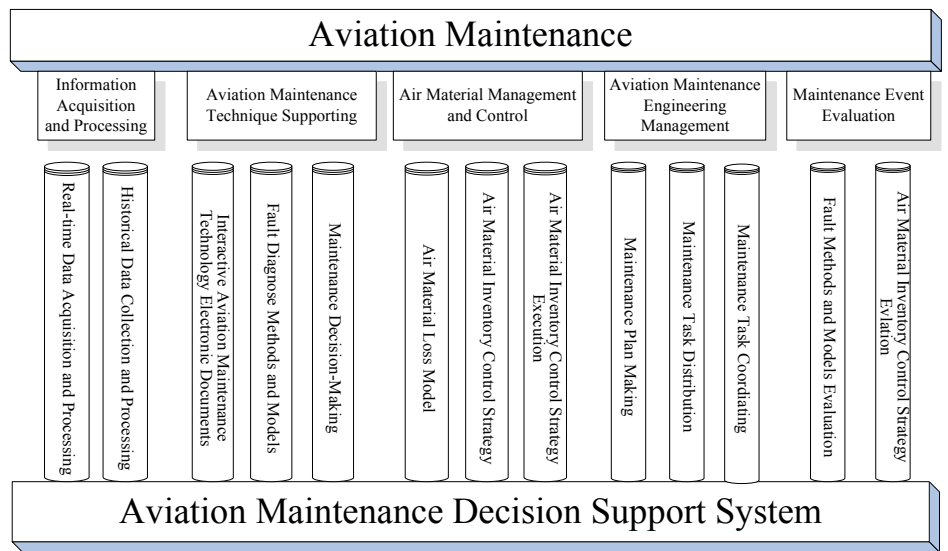

Fig. 1. Aviation maintenance decision system diagram

\subsubsection{Historical data acquisition and processing}

The process of aviation maintenance will accumulate a large amount of historical data. These data can be divided into three types, as shown in Figure 2.

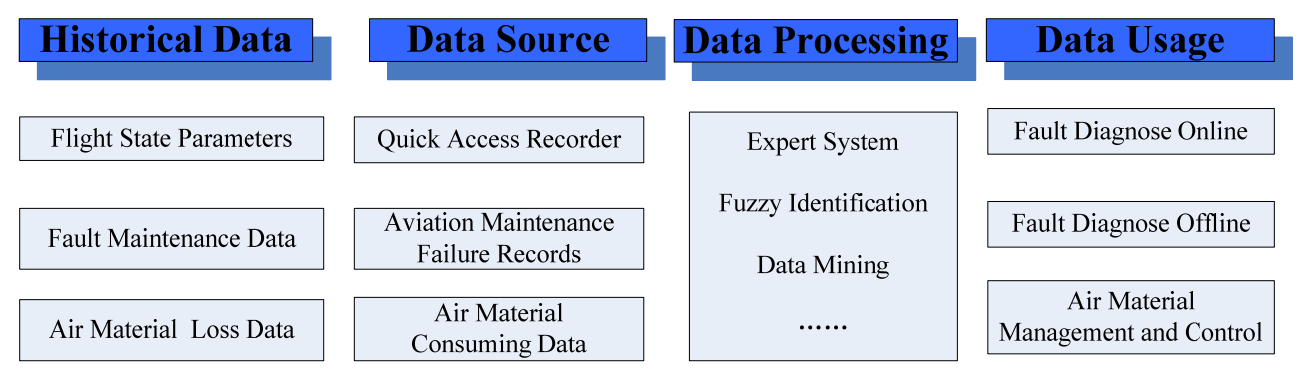

Fig. 2. Historical data acquisition and processing diagram

1. State parameters information of the flight is usually closely linked to aircraft failure recorded by Quick Accesses Recorder (QAR), through the in-depth analysis of recorded flight status parameters, we can learn the condition of airplane in flight. Using the causal relationship between the system failure symptoms and the cause of the malfunction, we can create online aircraft fault diagnosis model to provide decision support for online aircraft fault diagnosis, and based on which establish a on-board fault diagnosis system. 
2. Aircraft maintenance records are the depiction of the overall evolution of the aircraft and systems. Aircraft maintenance record data can be used to obtain deep relationship between the system failure symptoms and the cause of the malfunction, it becomes particularly useful when comes to learn the relationship between system and environment, and the interaction chain relationships between system and system, that makes it possible to conduct more comprehensive and in-depth fault diagnosis on the basis of online fault diagnosis, so as to provide firm decision support for the ground maintenance.

3. Air material is the material of aviation maintenance, in order to achieve the complexity capabilities and high-performance of modern aircraft, there are many types of aircraft systems, while different types of air material have different price, different loss of regularity and different storage conditions (the required temperature, humidity, storage time). Thus the improper selection of air material control strategy may lead to deficiency or excess of air material, on the other hand, if make good use of air material historical consumption data, then we can understand the status of air material loss and establish an appropriate procurement strategy to maintain a reasonable level of air material reserve, to improve aviation material utilization and the efficiency of enterprises.

\subsection{Aviation maintenance technical support}

Aviation maintenance technical support modules are based on the collected and processed data and the existing maintenance resources. Specifically, it can be divided into two aspects:

\subsubsection{The fault diagnosis model and method}

Fault diagnosis model is divided into on-line and off-line diagnosis model. On-line diagnosis model receives history aircraft state parameters from data acquisition and processing module, through data acquisition and processing module for the aircraft state parameters of the process history data, using more sophisticated expert system, fuzzy identification and other traditional fault diagnosis, established to identify different systems and components of the on-line fault diagnosis model based on the case of actual operation, can be used time of diagnosis, diagnostic accuracy and other parameters on-line fault diagnosis model to evaluate the results based on evaluation of diagnostic model of the online database to be updated. In addition, based on economic considerations, it should also be established on-line diagnosis based on Minimum Equipment List (MEL), Maintenance Steering Group 3 (MSG-3), etc. to develop appropriate law judge to determine the "serious failure" of the fault code list immediately through the ACARS system, then it will be transferred to the fault code list issued ground, or for storage, such as the plane landed using WirelessFidelity / Personal Digital Assistant (WiFi/PDA) and other technical means of transmission fault code list, reducing the flow of ground data link and improve the efficient use of ground data link.

Off-line fault diagnosis model based on information acquisition and processing module of the aircraft maintenance record information obtained through in-depth analysis of the system fault laws, particularly between the system and the environment, systems and crosslinking between the laws of the system, the establishment of fault symptoms, and the causal relationship between the fault types, the use of artificial neural network, Petri net fault diagnosis technology of modern aircraft comprehensive diagnostic data. Diagnosis entered 
into the aviation maintenance technical documentation for the interactive system, direct access to a viable maintenance program.

In addition, according to the system with historical fault data can also use trend analysis, curve fitting, time series and other methods for different types of faults predict the trend predicted results using the fault diagnosis can be assessed for failure diagnostic support.

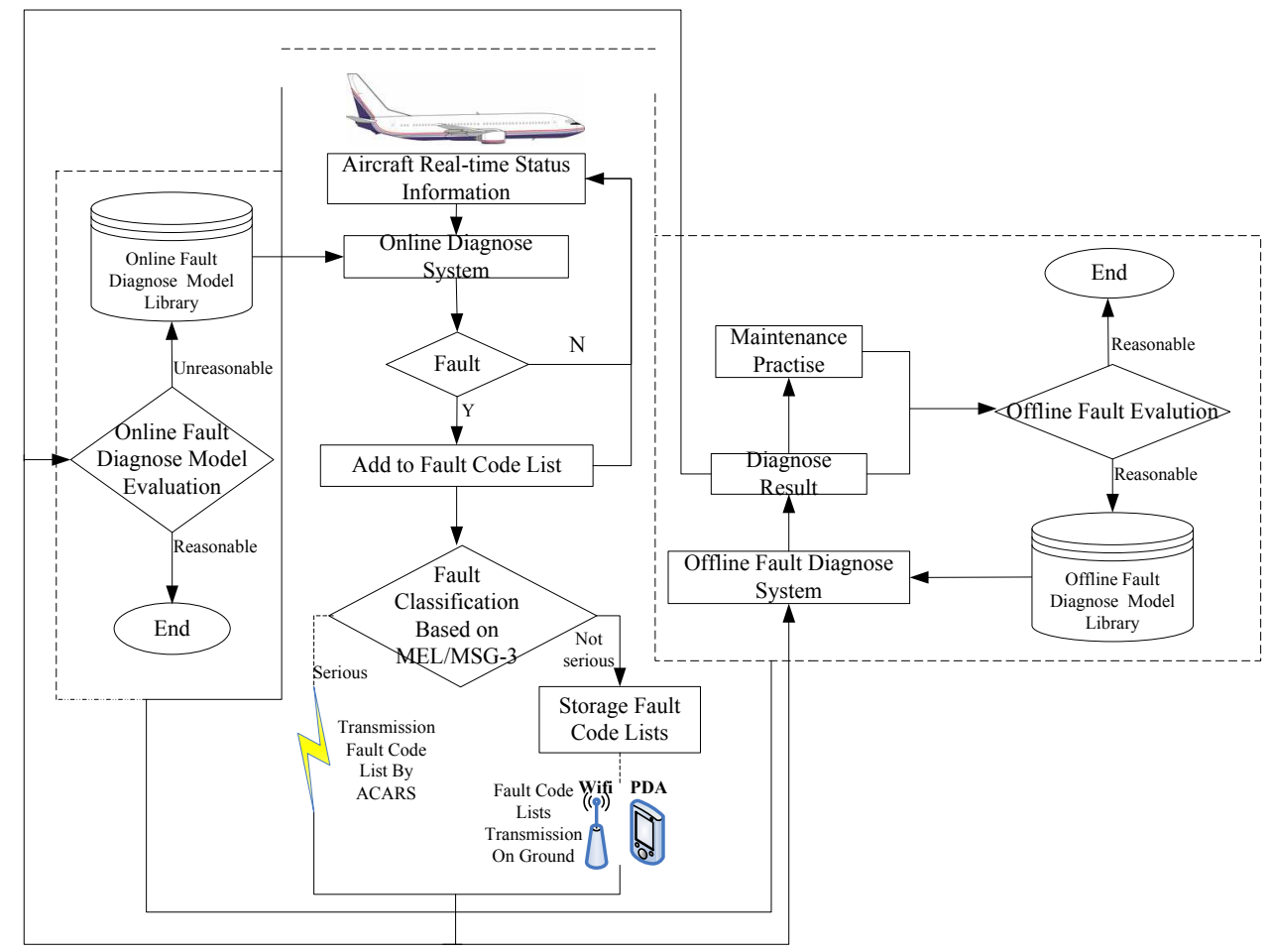

Fig. 3. Diagram of air-ground fault diagnosis

\subsubsection{Maintenance technical documentation}

The aviation maintenance technical documentation is another important aspect of aviation maintenance technical support, In particular, maintenance of aviation interactive electronic documents. Modern aircraft is an integrated body of advanced manufacturing technology, process technology, and information technology. It produces and uses lots of technical information in the design, production, use and maintenance process, for example, data from the manufacturer including Aircraft Maintenance Manual(AMM), Fault Reporting Manual (FRM), Fault Isolation Manual (FIM), Wiring Diagram Manual (WDM), System Scheme Manual (SSM), Illustrated Parts Catalogs (IPC), Master Minimum Equipment List (MMEL), etc; technical data from time to time update including Service Bulletin (SB), Service Letter (SL), etc; council documents including Federal Aviation Regulations (FAR, CCAR),Advisory Circular (AC), Airworthiness Directives (AD), etc. According to their own conditions, Airlines refer to the manufacturer and the requirements of the council to develop various 
documents, which are the important tools and resources to support the maintenance, for example, Minimum Equipment List (MEL), Operations Specifications (OS), Technology Policy and Procedures Manual (TPPM), Check Manual (TM), Outline Reliability Manual (RPM). Traditionally, many of these technical documents use paper for the storage medium, or in part, have been digitized, but a large number of technical documents have problems of queries difficult, not easy to carry and preservation and difficult to update.

Interactive aviation maintenance technical manual integrates advantages of technology of application computer, multimedia, database and network, organize and manage complex content operating manuals and maintenance information according to relevant standards, implement accurate performance of required information of maintenance staff with optimized way. The purpose of it is to accelerate the progress of aviation maintenance, enhance the effectiveness of maintenance.

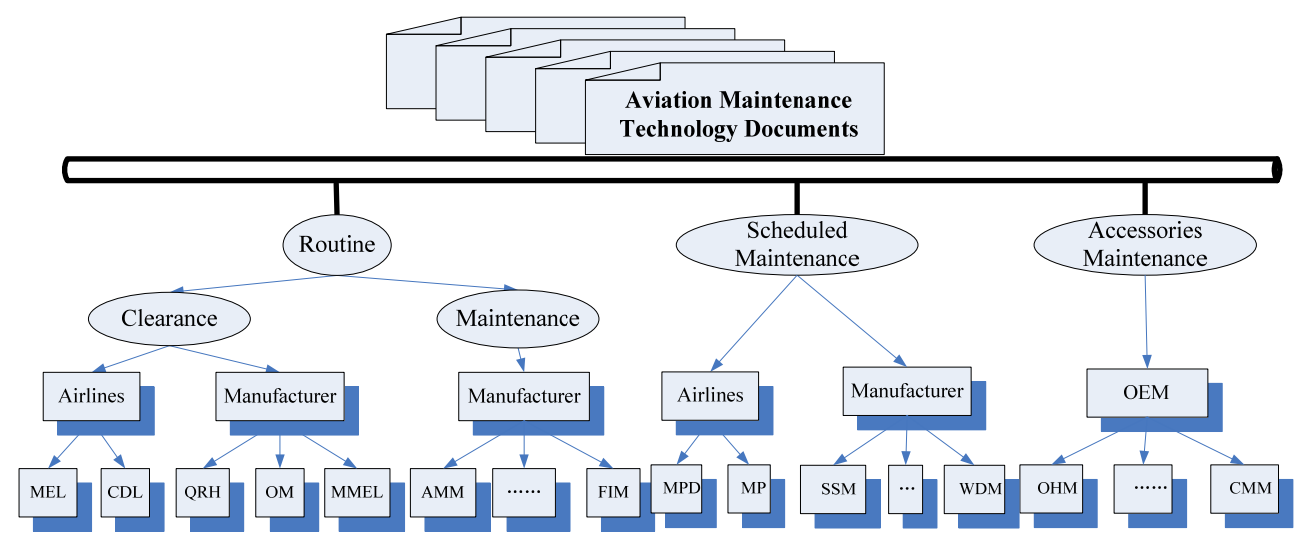

Fig. 4. The type of maintenance technology documents

\subsection{Management and control of air materiel}

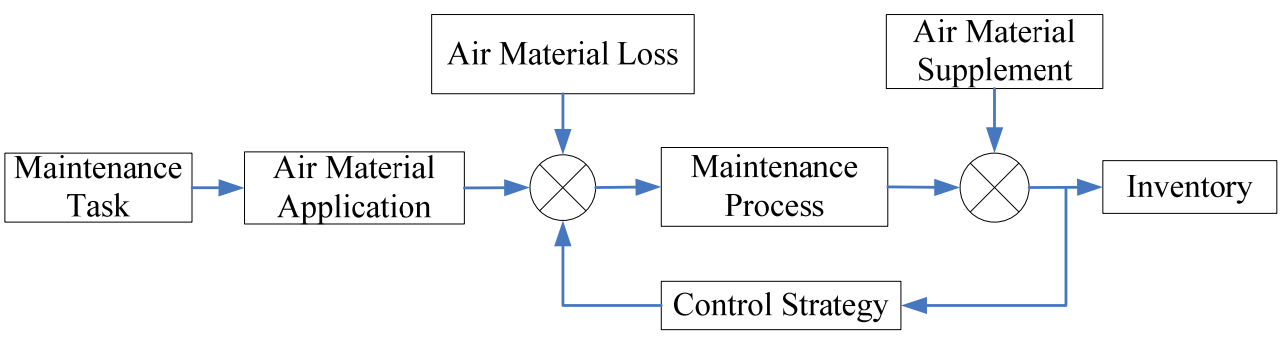

Fig. 5. Management and control of air materiel modelling

Air material inventory, which is the highest cost in aviation maintenance process, is an important component of aviation maintenance process for the complexity of modern aircraft components, variety of aircraft types and materials, and the use of different rules of air material, different storage requirements and flight safety. Therefore, control of air material has great influence on the efficiency of enterprises. Through we use historical information 
for information acquisition and processing module to get air materiel, it can gain the regularity of loss and buy of air materials using techniques of statistical analysis and data mining, such as the loss regularity of repairable air materials and unrepairable air materials, the maintained regularity of maintained air materials, etc., then through the rational control strategy, it establishes the corresponding loss mode, implements optimization of air material inventory and improve the quality of maintenance.

In addition, air material inventory control should consider the method of shared regional aviation maintenance units, especially with high value, and there may be more serious problems with lack of critical flight equipment, such as aircraft engines, etc. Through modeling and analysis of historical data, it can construct a reasonable model for regional air material sharing, and then contribute to enhance the efficiency of the industry for the whole region.

\subsubsection{Aviation maintenance management}

Aviation maintenance management is divided into maintenance program development, allocation of maintenance tasks, and maintenance tasks scheduling. Under the premise of security, the main goal of aviation maintenance is economic. A fast, highly reliable maintenance can increase the number of aircraft flight hours, thereby enhancing economic efficiency. Aviation Maintenance Management Module manages and controls the maintenance project based on the summarization of maintenance tasks from technical support module.

Maintenance plan is the core of maintenance tasks. It determines the implementation of maintenance methods based on the level of maintenance tasks, the existing maintenance resources (manpower, equipment, facilities, material, etc.) and the aircraft status. Maintenance plan includes many aspects, such as carrying out step by step or in parallel ways, the name of maintenance, repair content, maintenance workers, and materials required for the maintenance, etc. Maintenance plan makes reasonable arrangements for the future state of repair to ensure the smooth implementation of aviation maintenance.

Concrete repair work is completed by mechanical, electronic, structural, accessories maintenance workshop. The allocation of maintenance tasks are to maintain a reasonable distribution of work to the appropriate workshop, to enable the repair shops carrying out the maintenance work step by step or in parallel way and ensure the smooth progress of maintenance projects.

In the actual maintenance projects, maintenance programs will inevitably be adjusted, because the schedule might be unreasonable, or something's comes up as emergency or accident. Maintenance scheduling is to use reasonable scheduling strategy and appropriate decompose or combine maintenance tasks or just change the sequence to ensure the smooth implementation of maintenance works in accordance with the progress of the plan.

\subsubsection{Maintenance results evaluation}

Aviation maintenance decision support system is an open system. To achieve an objective and reasonable assessment, there should be a reasonable maintenance event parameters evaluation system, thus achieving optimal and update maintenance decision support system. Evaluation of maintenance events should contain at least three aspects: (1) Applicability of on-line fault diagnosis model. On-line fault diagnosis system is an on-board system, so its diagnosis should be real time and needs clear failure description while its 
relative diagnosis accuracy is not high. (2) The applicability of off-line fault diagnosis model. Off-line fault diagnosis system has sufficient resources and time to judge the on-line diagnosis system's results in detail, therefore, off-line fault diagnosis system is not critical on the diagnosis time, but the accuracy of diagnosis must be high, thus reasonable maintenance tasks can be determined, therefore, the effectively maintenance can be implemented and maintenance costs will be reduced. (3) Reasonable air materiel control model. Air material involves in various aspects, such as mechanical components, electronic components, and there are repair materials and maintenance consumables. Reasonable air materiel configuration not only meets the maintenance requirements, but also reduces the cost from procurement, storage, transportation, etc. Otherwise the airline may have a very negative impact on operations.

\section{Theory and examples of decision support system of aviation maintenance}

The decision support system of aviation maintenance, which has the properties of discrete event dynamic systems and continuous time dynamic system, is a typical hybrid system. The system of acquisition and processing of real-time data should contain functions of the acquisition of parameters information, filtering, transformation and so on, and it should use theory of continuous variable dynamic systems to construct, while acquisition and processing of history data mostly use relevant theories of statistics and analysis. It contains a lot of people work in the system of management and control of air materials, such as maintenance process, procurement process, etc., and has obvious properties of discrete event dynamic system, but through reasonable conversion, it can use a variety of modern control methods of minimum variance control, optimal control, stochastic control, adaptive control and robust control to implement. Aviation maintenance technical documents may pay more attention to technology and theory of multimedia, database/data warehouse. Simultaneously, because systems using discrete event dynamic system property can not be expressed using the traditional problem of parsing, it can use intelligence theory to solve, for example, fault diagnosis can use theories of neural network, Petri nets, fuzzy reasoning, agent, and so on.

With the development of theory and technology of computer simulation, it can use more approaches for the research of the model and method of aircraft fault diagnosis, the model of air materiel use and the air material inventory control, decision support system of aviation maintenance, and use full-simulation analysis of the system to establish a rational and efficient decision support system for aviation maintenance. The following is a certain type of aviation turbine jet engine fault diagnosis model of aircraft tire building process and inventory control process as an example.

\subsection{Aircraft fault diagnose based on adaptive FPN}

Aero-engine, which has structural complexity, possesses a number of components, works in the high temperature and harsh environment, so it may be fault anytime. When there is fault, because of the number of similar fault, it makes difficulties for aero-engine troubleshooting. For example, a certain type of air carrier turbojet has the fault of fuel consumption of large slip, it can use adaptive Fuzzy Petri Nets (FPN) to establish fault diagnosis model to position the cause of such fault. The process of model setting up as follows: 
(1) The definition of model input variables and output variables, the model input variables is the logic state of fault symptoms, defining as

$$
X=\left[\begin{array}{lllllll}
x_{1} & x_{2} & x_{3} & x_{4} & x_{5} & x_{6} & x_{7}
\end{array}\right],
$$

The meaning as shown in table 1 ; model output variables is degree of confidence of fault causes, defining as

$$
Y=\left[\begin{array}{lllll}
y_{1} & y_{2} & y_{3} & y_{4} & y_{5}
\end{array}\right],
$$

The meaning is as shown in table 2.

\begin{tabular}{c|c|c|c|c}
\hline \hline Variable name & $x_{1}$ & $x_{2}$ & $x_{3}$ & $x_{4}$ \\
\hline $\begin{array}{c}\text { Symptom of } \\
\text { Phenomenon }\end{array}$ & $\begin{array}{c}\text { Oil in nozzle at } \\
\text { the bottom of } \\
\text { turbine }\end{array}$ & $\begin{array}{c}\text { Oil at compressor } \\
\text { entrance, fore tank } \\
\text { bottom skin }\end{array}$ & $\begin{array}{c}\text { Oil at } \\
\text { airplane } \\
\text { tail cone }\end{array}$ & $\begin{array}{c}\text { White smoking } \\
\text { at aft pressure } \\
\text { reducer }\end{array}$ \\
\hline Variable Name & $x_{5}$ & $x_{6}$ & $x_{7}$ \\
\hline $\begin{array}{c}\text { Symptom of } \\
\text { Phenomenon }\end{array}$ & $\begin{array}{c}\text { Oil beads at } \\
\text { centrifugal } \\
\text { ventilator's vent }\end{array}$ & $\begin{array}{c}\text { Ejector tube } \\
\text { emitting purple } \\
\text { smoke }\end{array}$ & $\begin{array}{c}\text { Flight in the air, oil } \\
\text { consumption heavy }\end{array}$ \\
\hline \hline
\end{tabular}

Table 1. Definition of fault symptom and input variables

\begin{tabular}{c|c|c|c|c|c}
\hline \hline $\begin{array}{c}\text { Variable } \\
\text { Name }\end{array}$ & $y_{1}$ & $y_{2}$ & $y_{3}$ & $y_{4}$ & $y_{5}$ \\
\hline $\begin{array}{c}\text { Fault } \\
\text { Cause }\end{array}$ & $\begin{array}{c}\text { Oil pump's } \\
\text { one-way } \\
\text { valve not } \\
\text { sealing }\end{array}$ & $\begin{array}{c}\text { One-way valve of } \\
\text { radiator interface not } \\
\text { sealing }\end{array}$ & $\begin{array}{c}\text { Centrifugal } \\
\text { valve } \\
\text { membrane } \\
\text { rupture }\end{array}$ & $\begin{array}{c}\text { In bearing } \\
\text { cavity, } \\
\text { pressure too } \\
\text { high }\end{array}$ & $\begin{array}{c}\text { Three class } \\
\text { scavenging } \\
\text { pump } \\
\text { inefficient }\end{array}$ \\
\hline \hline
\end{tabular}

Table 2. Definition of fault cause and output variables

(2) Initializing the model parameters, membership parameters of input fault symptoms and fault cause, this is given by the expert system and repair factory's statistical data, respectively set to

$$
D_{0}=\left[\begin{array}{lllllll}
d_{01} & d_{02} & d_{03} & d_{04} & d_{05} & d_{06} & d_{07}
\end{array}\right] \text { and } D_{0}=\left[\begin{array}{lllllll}
d_{11} & d_{12} & d_{13} & d_{14} & d_{15} & d_{16} & d_{17}
\end{array}\right],
$$

as shown in table 3 and table 4 .

(3) According to the fuzzy inference rules of FPN, it defines network algorithms on each floor, uses the maximum degree of membership and the principle of membership grade threshold $(\gamma>0.8)$ and combines with the definition of fuzzy algorithms to construct the fault diagnosis model FPN.

(4) According to the actual maintenance condition, amend membership between fault symptom and fault causes in initial model parameters, and the amendment formula is as follows: 


$$
d_{1 i}=\left\{\frac{\text { times of } i \text { symptom which belong to } j \text { reason }}{\text { the total times of } i \text { symptom }}\right\}
$$

The parameters mean $i=1,2, \cdots, 7 ; j=1,2, \cdots, 5$. It can make FPN amend model parameters online in accordance with fault occurrence.

\begin{tabular}{|c|c|c|c|c|c|c|c|c|c|c|c|c|}
\hline \multicolumn{7}{|c|}{ Fault Symptom $x_{i}$} & \multirow{2}{*}{ Membership Grade $d_{0 i}$} & \multicolumn{5}{|c|}{ Fault Cause $y_{i}$} \\
\hline$x_{1}$ & $x_{2}$ & $x_{3}$ & $x_{4}$ & $x_{5}$ & $x_{6}$ & $x_{7}$ & & $y_{1}$ & $y_{2}$ & $y_{3}$ & $y_{4}$ & $y_{5}$ \\
\hline 1 & 0 & 0 & 0 & 0 & 0 & 0 & $d_{01}$ & 0.65 & 0.35 & 0 & 0 & 0 \\
\hline 0 & 1 & 0 & 0 & 0 & 0 & 0 & $d_{02}$ & 0.30 & 0.50 & 0 & 0.20 & 0 \\
\hline 0 & 0 & 1 & 0 & 0 & 0 & 0 & $d_{03}$ & 0 & 0.20 & 0.75 & 0 & 0.05 \\
\hline 0 & 0 & 0 & 1 & 0 & 0 & 0 & $d_{04}$ & 0.30 & 0 & 0 & 0.56 & 0.14 \\
\hline 0 & 0 & 0 & 0 & 1 & 0 & 0 & $d_{05}$ & 0.20 & 0 & 0.50 & 0.30 & 0 \\
\hline 0 & 0 & 0 & 0 & 0 & 1 & 0 & $d_{06}$ & 0.47 & 0 & 0.28 & 0 & 0.25 \\
\hline 0 & 0 & 0 & 0 & 0 & 0 & 1 & $d_{07}$ & 0.10 & 0.30 & 0 & 0 & 0.60 \\
\hline
\end{tabular}

Table 3. The membership grade relationship statistics between fault symptoms and fault causes in the repair factory

\begin{tabular}{|c|c|c|c|c|c|c|c|c|c|c|c|c|}
\hline \multicolumn{7}{|c|}{ Fault Symptom $x_{i}$} & \multirow{2}{*}{ Membership Grade $d_{0 i}$} & \multicolumn{5}{|c|}{ Fault Cause $y_{i}$} \\
\hline$x_{1}$ & $x_{2}$ & $x_{3}$ & $x_{4}$ & $x_{5}$ & $x_{6}$ & $x_{7}$ & & $y_{1}$ & $y_{2}$ & $y_{3}$ & $y_{4}$ & $y_{5}$ \\
\hline 1 & 0 & 0 & 0 & 0 & 0 & 0 & $d_{11}$ & 0.80 & 0.20 & 0 & 0 & 0 \\
\hline 0 & 1 & 0 & 0 & 0 & 0 & 0 & $d_{12}$ & 0.20 & 0.65 & 0 & 0.15 & 0 \\
\hline 0 & 0 & 1 & 0 & 0 & 0 & 0 & $d_{13}$ & 0 & 0.20 & 0.80 & 0 & 0 \\
\hline 0 & 0 & 0 & 1 & 0 & 0 & 0 & $d_{14}$ & 0.25 & 0 & 0 & 0.70 & 0.05 \\
\hline 0 & 0 & 0 & 0 & 1 & 0 & 0 & $d_{15}$ & 0.12 & 0 & 0.20 & 0.68 & 0 \\
\hline 0 & 0 & 0 & 0 & 0 & 1 & 0 & $d_{16}$ & 0.22 & 0 & 0.66 & 0 & 0.12 \\
\hline 0 & 0 & 0 & 0 & 0 & 0 & 1 & $d_{17}$ & 0.22 & 0.10 & 0.10 & 0 & 0.58 \\
\hline
\end{tabular}

Table 4. Expert database of membership grade relations between fault symptoms and fault causes

According to the above flow, adaptive FPN fault diagnosis model is set up as shown in Figure 6. Using MATLAB and 18 fault symptom state vectors, simulation is carried out, simulation results and the actual cause confirmed in maintenance as shown in Table 5, the diagnostic accuracy rate is $100 \%$. This shows that the reliability of model diagnosis is relatively high. On the other hand, item 7 and 10, there are some deviation between output of fault model diagnosis and result of actual maintenance, because take method of threshold membership grade to eliminate fuzzy, diagnostic efficiency little decreases, but at the same time to avoid impact of random factors, which could result in the deviation of diagnostic results. 


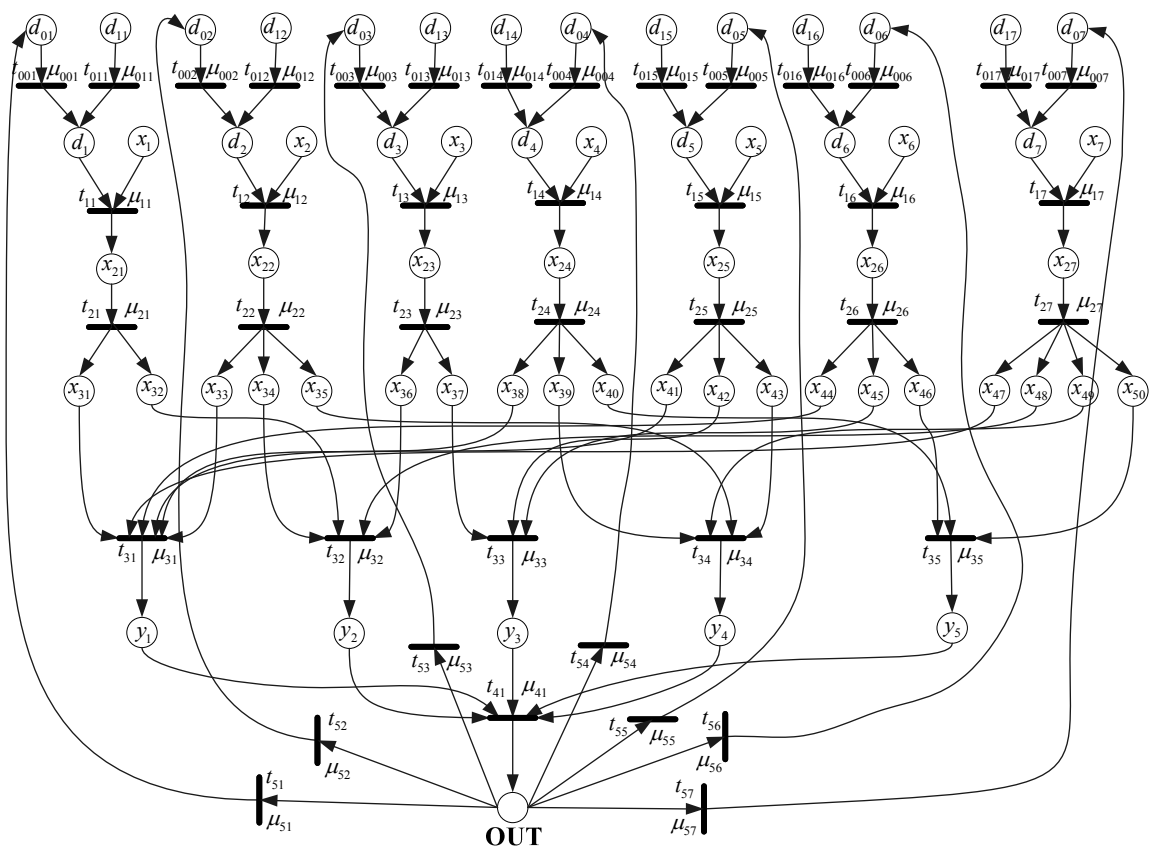

Fig. 6. Fault diagnosis model of adaptive FPN

\begin{tabular}{|c|c|c|c|c|c|c|}
\hline Serial Number & 1 & 2 & 3 & 4 & 5 & 6 \\
\hline $\begin{array}{c}\text { Fault Symptom } \\
\text { Matrix X }\end{array}$ & {$\left[\begin{array}{llllll}0 & 1 & 0 & 1 & 0 & 0\end{array}\right]$} & {$\left[\begin{array}{lllllll}1 & 0 & 0 & 0 & 1 & 0 & 0\end{array}\right]$} & {$\left[\begin{array}{llllll}0 & 1 & 1 & 0 & 0 & 0\end{array}\right]$} & {$\left[\begin{array}{lllllll}1 & 0 & 0 & 1 & 0 & 0 & 0\end{array}\right]$} & {$\left[\begin{array}{lllllll}1 & 0 & 1 & 0 & 0 & 0 & 0\end{array}\right]$} & {$\left[\begin{array}{llllll}1 & 0 & 0 & 0 & 0 & 0\end{array}\right]$} \\
\hline Diagnosis Cause & $y_{4}$ & $y_{4}$ & $y_{2}$ & $y_{1}$ & $y_{3}$ & $y_{1}$ \\
\hline Actual Cause & $y_{4}$ & $y_{4}$ & $y_{2}$ & $y_{1}$ & $y_{3}$ & $y_{1}$ \\
\hline Serial Number & 7 & 8 & 9 & 10 & 11 & 12 \\
\hline $\begin{array}{c}\text { Fault Symptom } \\
\text { Matrix } X\end{array}$ & {$\left[\begin{array}{llllll}1 & 1 & 0 & 0 & 0 & 0\end{array}\right]$} & {$\left[\begin{array}{lllllll}0 & 0 & 1 & 0 & 0 & 1 & 0\end{array}\right]$} & {$\left[\begin{array}{llllll}1 & 0 & 1 & 0 & 0 & 0\end{array}\right]$} & {$\left[\begin{array}{lllllll}0 & 1 & 0 & 1 & 0 & 1 & 0\end{array}\right]$} & {$\left[\begin{array}{lllllll}1 & 0 & 0 & 0 & 0 & 1 & 0\end{array}\right]$} & {$\left[\begin{array}{llllll}0 & 0 & 1 & 0 & 1 & 0\end{array}\right]$} \\
\hline Diagnosis Cause & $y_{1}, y_{2}$ & $y_{3}$ & $y_{1}, y_{3}$ & $y_{1}, y_{4}$ & $y_{1}$ & $y_{3}$ \\
\hline Actual Cause & $y_{2}$ & $y_{3}$ & $y_{1}, y_{3}$ & $y_{4}$ & $y_{1}$ & $y_{3}$ \\
\hline Serial Number & 13 & 14 & 15 & 16 & 17 & 18 \\
\hline $\begin{array}{c}\text { Fault Symptom } \\
\text { Matrix X }\end{array}$ & {$\left[\begin{array}{lllllll}0 & 0 & 1 & 1 & 0 & 1 & 0\end{array}\right]$} & {$\left[\begin{array}{lllllll}1 & 0 & 0 & 0 & 1 & 1 & 0\end{array}\right]$} & {$\left[\begin{array}{lllllll}0 & 0 & 0 & 1 & 0 & 0 & 1\end{array}\right]$} & {$\left[\begin{array}{lllllll}0 & 0 & 0 & 1 & 0 & 1 & 0\end{array}\right]$} & {$\left[\begin{array}{lllllll}0 & 1 & 0 & 1 & 1 & 0 & 0\end{array}\right]$} & 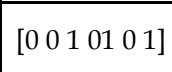 \\
\hline Diagnosis Cause & $y_{3}$ & $y_{1}, y_{3}$ & $y_{5}$ & $y_{4}$ & $y_{4}$ & $y_{3}$ \\
\hline Actual Cause & $y_{3}$ & $y_{1}, y_{3}$ & $y_{5}$ & $y_{4}$ & $y_{4}$ & $y_{3}$ \\
\hline
\end{tabular}

Table 5. Comparison table of model diagnosis result and actual cause 
Through the theory of adaptive FPN, it analyzes the cause of turbojet engine heavy oil consumption, sets up a heavy oil consumption fault symptoms - fault cause diagnostic model, and gives an intuitive expression of complex relationship between the fault cause and fault symptoms. It has reality significance to the aviation maintenance factory fast locating fault cause, improving maintenance efficiency and reducing maintenance costs of enterprises. And it also provides a new idea for the further development of the aviation maintenance decision-making support system.

\subsection{Tire inventory management and control model}

Suppose that the same type of aircrafts in a fleet of airline " $\mathrm{A}$ " consume and replace tires everyday, amount of which is $X_{1}(\mathrm{k})$ ( $\mathrm{k}$ is a date serial number ), and $X_{1}(\mathrm{k})$ is the random process. Considering the regularity of flights, we can think that there is no relationship between loss of statistical laws of tires and dates from the engineering point of macro view. At the same time, it is considered that the amount of tire loss of any day does not affect the amount of tire loss of any day in the future, that is, $X_{1}(\mathrm{k})$ and $X_{1}(\mathrm{k}+1)(\mathrm{h} \neq 0)$ are independent.

Based on above given conditions, obviously, tires required changing everyday is followed Poisson distribution, so it is a Poisson process. For controlling air material tires inventory needs new tires supplement at a certain period, or refresh used tires. Set the period is $M$ days, we should consider the statistical character of process $X_{M}(\mathrm{k})=X_{1}(\mathrm{k})+X_{1}(\mathrm{k}+1)+\cdots \cdots$ $+X_{1}(\mathrm{k}+\mathrm{M}-1) \cdot X_{1}(\mathrm{k}), X_{1}(\mathrm{k}+1), \cdots \cdots, X_{1}(\mathrm{k}+\mathrm{M}-1)$ is independent of each other, followed the same distribution, and has limited mathematical expectation and variance. According to central limit theorem, when $M$ tends to infinity (actually, as long as $M$ is enough large) $X_{M}$ $(k)$ obeys the normal distribution. It is that $X_{\mathrm{M}}(\mathrm{k})$ is followed normal random process.

It should be noted that the different fleets, different aircrafts have different $X_{1}(\mathrm{k})$. As different airlines with different route, taking off and landing frequency of flights are quite different every day from twice a day to dozen a day, and different aircrafts may have a huge difference in tire wear, therefore, the tire's loss properties statistical of different fleet are different.

After the acquisition of air material inventory and maintenance data from a number of airlines, it uses Statistical Product and Service Solutions (SPSS), MATLAB and other software for data statistical processing. A case of airline " $\mathrm{A}$ " is analyzed. We use the tire loss data of a fleet which includes ten same aircrafts from March 1, 2008 to November 1, 2008. After data analysis, there are tables as follows, Table 6 is about the data, and Table 7 is about the results of fitting analysis with normal process, even process, Poisson process, and exponential process.

Analysis below shows:

1. From Table 7, tires loss process is a random process and has a very high fitting degree with Poisson process.

2. As can be seen from Table 7, with the increase in computing cycles, the fitting degree with the normal process is increasing.

3. From the autocorrelation analysis, we learn that when the delay is 0 , the correlation coefficient is 1 , the relevant degree is less than 0.2 under the rest delay.

We can get the conclusion from below analysis as follows:

1. Taking the date serial number as the independent variable, tires loss time-series can be handled as a Poisson process. 
2. Tire loss data correlation is weak between different days. Thus from an engineering point of view, the loss of tire number of different dates are independent.

3. With the increase of computing cycles, random distribution tends to normal distribution. Application of engineering control theory to solve the problem of optimal inventory seems necessary.

\begin{tabular}{|c|c|c|c|c|c|c|}
\hline Date & Quantity & 3 Days & 7 Days & 10 Days & 20Days & \\
\hline 3.1 & 1 & \multirow{3}{*}{2} & \multirow{7}{*}{2} & \multirow{10}{*}{3} & & \\
\hline 3.2 & 1 & & & & & \\
\hline 3.3 & 0 & & & & & \\
\hline 3.4 & 0 & \multirow{3}{*}{0} & & & & \\
\hline 3.5 & 0 & & & & & \\
\hline 3.6 & 0 & & & & & \\
\hline 3.7 & 0 & \multirow{3}{*}{1} & & & & \\
\hline 3.8 & 1 & & \multirow{7}{*}{2} & & & \\
\hline 3.9 & 0 & & & & & \\
\hline 3.10 & 0 & \multirow{3}{*}{1} & & & & \\
\hline 3.11 & 1 & & & \multirow{10}{*}{4} & & \\
\hline 3.12 & 0 & & & & & \\
\hline 3.13 & 0 & \multirow{3}{*}{2} & & & & \\
\hline 3.14 & 0 & & & & & Fat \\
\hline 3.15 & 2 & & \multirow{7}{*}{3} & & $\cdots \cdots$ & \\
\hline 3.16 & 0 & \multirow{6}{*}{0} & & & & \\
\hline 3.17 & 1 & & & & & \\
\hline 3.18 & 0 & & & & & \\
\hline 3.19 & 0 & & & & & \\
\hline 3.20 & 0 & & & & & \\
\hline 3.21 & 0 & & & \multirow{9}{*}{2} & & \\
\hline 3.22 & 1 & \multirow{3}{*}{1} & \multirow{7}{*}{2} & & & \\
\hline 3.23 & 0 & & & & & \\
\hline 3.24 & 0 & & & & & \\
\hline 3.25 & 0 & \multirow{3}{*}{1} & & & & \\
\hline 3.26 & 0 & & & & & \\
\hline 3.27 & 1 & & & & & \\
\hline 3.28 & 0 & \multirow{2}{*}{0} & & & & \\
\hline 3.29 & 0 & & 4 & & & \\
\hline
\end{tabular}

Table 6. The fleet tires loss situation (2008.3.1-2008.11.1) 
Excessive tire inventory will increase storage costs, administrative costs, regular test costs and renovation costs, etc. On the other hand, the lack of tire inventories will cause difficulty in timely maintenance and affect the flight delays, and cause economic and social loss, thus, the optimal inventory levels need to be determined.

\begin{tabular}{|c|c|c|c|c|}
\hline Period & $\begin{array}{c}\text { Normal Process } \\
\text { Fitting Degree }\end{array}$ & $\begin{array}{c}\text { Uniform Process } \\
\text { Fitting Degree }\end{array}$ & $\begin{array}{c}\text { Poisson Process } \\
\text { Fitting Degree }\end{array}$ & $\begin{array}{c}\text { Index Process } \\
\text { Fitting Degree }\end{array}$ \\
\hline 1 Day & 0.000 & 0.000 & 0.981 & 0.000 \\
\hline 3 Days & 0.001 & 0.000 & 1.000 & 0.000 \\
\hline 7 Days & 0.351 & 0.000 & 0.999 & 0.001 \\
\hline 10 Days & 0.862 & 0.147 & 1.000 & 0.027 \\
\hline 20 Days & 0.781 & 0.180 & 0.930 & 0.011 \\
\hline
\end{tabular}

Table 7. Fitting degree of tires loss data compared to different stochastic process

Figure 7 to Figure 10 shows the correlation analysis result of data

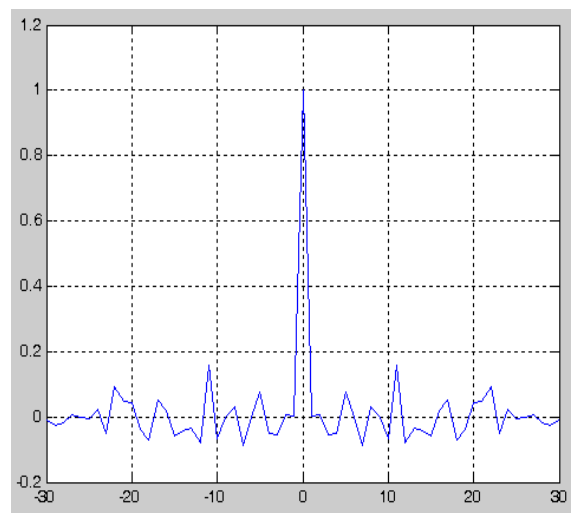

Fig. 7. Auto-correlation at period of 1 day

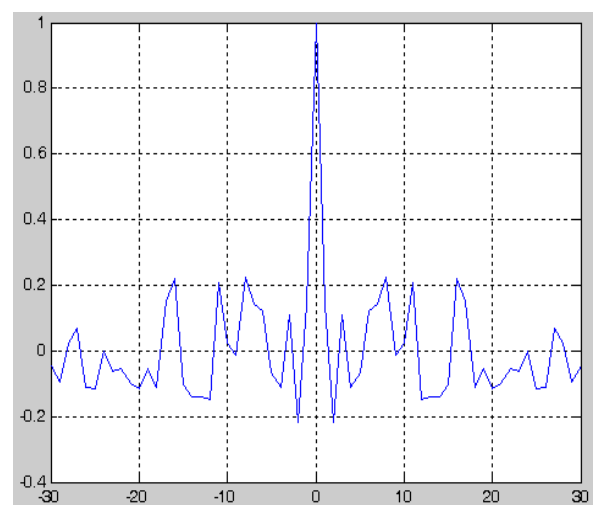

Fig. 9. Auto-correlation at period of 7 days

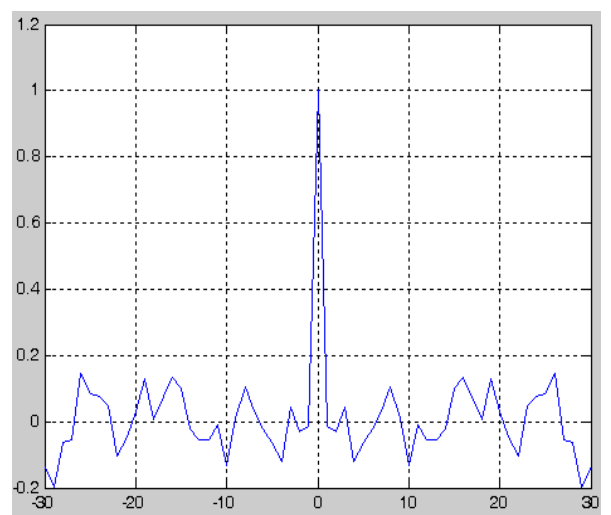

Fig. 8. Auto-correlation at period of 3 days

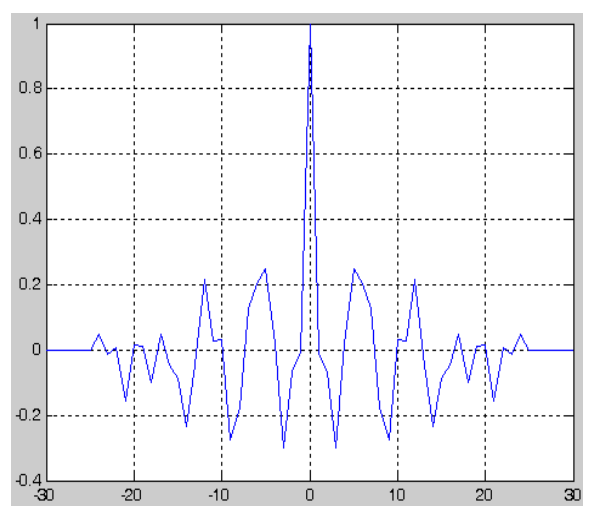

Fig. 10. Auto-correlation at period of 10 days 
Considering the long period of tire repair, we take tire inventory as a normal distribution process. Table 8 is the assumptions and parameters of the optimal inventory analysis.

\begin{tabular}{|c|c|}
\hline Symbol & Descriptions of volume and parameter \\
\hline$N_{0}$ & Average inventory \\
\hline$\sigma$ & Stock volume variance \\
\hline$G_{1}$ & Inventory costs $(100 ¥ /$ a tire $)$ \\
\hline$G_{2}$ & The loss of delay for the lack of tires $(10000 ¥ /$ a tire $)$ \\
\hline$k$ & Number of tires \\
\hline$F$ & Total cost \\
\hline
\end{tabular}

Table 8. Analysis of assumptions and parameters of the optimal inventory

Because the event of tires shortage is a small probability event, it sets inventory costs for $\mathrm{N}_{0} \mathrm{G}_{1}$. For convenience of calculating, it is considered that the number of lack tires is no more than 5, and corresponding loss of the lack of tires is as follows:

$$
G_{2} \sum_{k=1}^{5} k \frac{1}{\sqrt{2 \pi} \sigma} e^{-\frac{\left(-k-N_{0}\right)^{2}}{2 \sigma^{2}}}=G_{2} \sum_{k=1}^{5} \frac{k}{\sqrt{2 \pi} \sigma} e^{-\frac{\left(k+N_{0}\right)^{2}}{2 \sigma^{2}}}
$$

Then total cost is:

$$
F=N_{0} G_{1}+G_{2} \sum_{k=1}^{5} \frac{k}{\sqrt{2 \pi} \sigma} e^{-\frac{\left(k+N_{0}\right)^{2}}{2 \sigma^{2}}}
$$

As can be seen from the equation, when the average inventory increases, the first increase, the second reduction, when the average inventory reduction, the first decrease, while the second increase. When stocks Mean Square Error (MSE) is constant, it can calculate the optimal value of the average stock. Table 9 gives the MSE of different stocks and optimal average inventory.

\begin{tabular}{|c|c|c|c|c|c|c|c|c|c|}
\hline$\sigma$ & 1 & 2 & 3 & 4 & 5 & 6 & 7 & 8 & 9 \\
\hline$N_{0}$ & $2-3$ & $4-5$ & $6-7$ & $9-10$ & $11-12$ & $13-14$ & $14-15$ & $16-17$ & $18-19$ \\
\hline
\end{tabular}

Table 9. Optimal average inventory for the MSE of different stocks

Analysis above shows:

(1) Obviously, with the increase of the variance of inventory, optimal average inventory is straight up and inventory cost increases rapidly; (2) For different aircraft types, parameters has large difference, and inventory cost is not the same, so optimal inventory levels will be relatively large different; (3) It can be seen from qualitative analysis of the theory, when the period calculated increases, average inventory corresponding increases, then the MSE of stocks also increases, nonlinear relationship between the two, but not independent. Therefore, it uses the method of searching to solve the optimal value. Through theoretical 
analysis and experimental data analysis, it shows that the process of tire loss can be seen as independent Poisson process in engineering. When the period calculated (in fact, tire repair period) is large, it is considered that this process is independent normal random process. In addition, through the optimal analysis and calculation of optimal average inventory for the MSE of different stocks, it can be seen that if it uses the method of reducing the MSE of stock to control inventory, it can reduce the total cost.

\section{Prospects and challenges}

In recent years, based on widely using of the maintenance theory of on-condition, condition monitoring, etc., it proposes maintenance concepts, such as digital maintenance, proactive maintenance and so on, which supported by strong monitoring and diagnosis techniques to improve the efficiency of maintenance greatly, so there must be strong decision support system to construct modern aviation maintenance system.

MDSS can provide effective decision support for aviation maintenance. It also improves maintenance efficiency and controls maintenance costs. However, the aviation MDSS still needs further research on the following topics:

1. Because modern aircraft has many systems and complex structure, many flight parameters need to monitor. How to build efficient database and research criteria for judging the effectiveness of real-time data should conduct further research.

2. Because real-time flight status data downloaded relate to cost problems, how to establish the fault information download criteria should conduct further research.

3. The system has a property of hybrid system, and there are many ways for DEDS and CVDS modeling, but theory and method of modeling the hybrid system is still needed to be improved, so how to organic combine CVDS system with DEDS system and modeling the hybrid system should conduct further research.

4. MDSS is closely related with the airline operating environment, as there are obvious differences between airlines, how to select appropriate parameters, and how to overcome the bad applicability should conduct further research.

\section{References}

Zhang Yalin. \& He Yizheng. (2007). Maintenance Information Management System. Avionics Technology, Vol.38, No.2, (June 2007), pp. 41-45

Qi Yanjie.; Lv Zhigang. \& Song Bifeng. (2008). Design for Maintenance on Modern Airplane. Journal of Civil Aviation University of China, Vol.26, No.5, (October 2008), pp. 5-9

Qi Yanjie.; Lv Zhigang. \& Song Bifeng. (2010). Ultimate Service Life : New Concept for Aircraft Life Management. Journal of Civil Aviation University of China, Vol.28, No.2, (April 2010), pp. 22-28

Harry A. Kinnison,Ph.D. (2004). Aviation Maintenance Management, The McGraw Hill Companies, Inc, ISBN 0-07-142251-X, New York, USA

Sun Li. (2008). Remote Management of Real-Time Airplane Data. Aviation Maintenance $\mathcal{E}$ Engineering, (January 2008)

Tan Xuehua. \& Wang Huawei. (2008). Research on Frame of Plane's Maintenance Programme Optimization. Computer Technology And Development, Vol.18, No.11 (Nov. 2008), pp. 183-186 
Zhu Rui. \& Xu Chunsheng.(2005). An Approach for Aircraft Long-Range Real-time Monitoring. Aviation MaintenanceEEngineering,(March 2005),pp.53-55

Zhang Peng. (2004). A Study of Aircraft Health Status Evaluation Based on Flight Data Trend Monitor. Journal of Air Force Engineering University(Natural Science Edition),(June 2004), Vol.5, No.3(June 2004), pp. 8-10

Zhu Yanbo.; Zhang Xiaolin. \& Tan Xijing. (2006). An Electronic Manual Analysis Method for Aircraft Maintenance Decision Supporting System. MaintenanceEEngineering,(April 2006),pp.28-30

Chang Fei.; Han Qing. \& Shang Bolin.(2008). Application of FBG on Flight Vehicle structural Heath Monitoring Systems. Science Technology and Engineering, Vol.8, No.10(May 2008), pp. 2641-2646

Sun Haidong. \& Lv Jian. (2009). On Critical Technologies for Health Management Expert System of Avionic System. Electronic Optics \& Control, Vol.16, No.7(May 2009), pp. $40-44$

Fu Keya. \& Li Benwei. (2006). Fuzzy Comprehensive Decision Method of Aero engine Maintenance. Aircraft engine, Vol.33, No.4(2007), pp.55-58

Ma Xiaofeng.(2009) Intelligent Decision Support Systems Design and Analysis of Aeronautic Equipment Maintenance. Control and Automation Publication Group, Vol.25, No.7(2009), pp. 25-27

Wang Yu. \& Wang Xiaofeng. (2001). Ship Maintenance Decision Support System Based on Data Base. Computer Aided Engineering, No.4 (Dec. 2001), pp. 6-14

Zhang Tao.; Guo Bo. \& Tan Yuejin.(2004). Research on a Mission oriented Maintenance Resources Deployment Decision Support System. Acta Armamentarii, Vol.26, No.5(2005), pp. 716-720

Cao Yu.; Liu Yile. \& Xu Zongchang.(2003). Realization of Visualization for Maintenance Intelligence. Computer engineering and design, Vol.24, No.5(May 2003), pp.50-52

Sun Ning. Airplane Health Management in Air China B747-400 fleet operation support. Maintenance, Vol.114(June 2010), pp.65-67

Zhu Rui. The Research for the Application of Data Mining in Aircraft Health Management. Information Technology, (April 2007), pp.36-38

Zhao Ruiyun. (2005). Concept and Application of Central Maintenance System. Avionics Technology, Vol.36, No.2(June 2005), pp. 14-18

Ye Yonglin.; Yang Xueqiang.; Huang Jun. \& Liu Xing. (2008) Model Base Design in Equipment Maintain ，Assistant Decision, Vol.22, No.4(Aug 2008), pp. $92-94$

Cao Zhiqiang.; Li Zhao. \& Han Hongwei. (2008) Research on Equipment Repairing Intelligent Decision Support System. Radio Engineering, Vol.38, No.12(2008), pp. 5-7

Hua Keqiang. \& Qu Wenfang.(2010). Aviation Supplies Inventory Data Analysis and the Study of the Optimal Inventory. Aviation Maintenance $\mathcal{E}$ Engineering, (April 2010),pp.68-70

LV Changling. \& Xie Bangchang. (2009). Data Mining Method \& Application, China Renmin University Press, ISBN978-7-300-09970-5, Beijing, China

Zhang Peng.; Zhao Shiwei. \& Wang Yake.(2009). The Research of Aircraft Fault Diagnosis Based on Adaptive FPN. Chinese control and decision conference, ISBN 978-1-42442723-9, China, June, 2009 


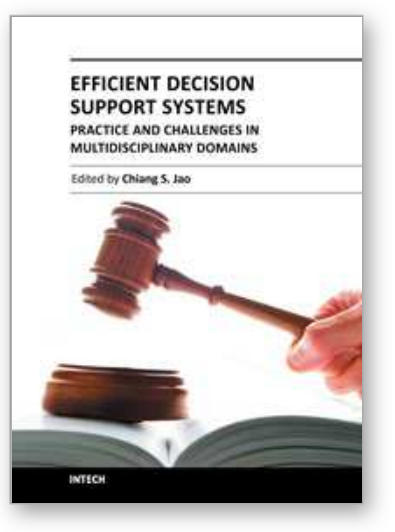

\author{
Efficient Decision Support Systems - Practice and Challenges in \\ Multidisciplinary Domains \\ Edited by Prof. Chiang Jao
}

ISBN 978-953-307-441-2

Hard cover, 478 pages

Publisher InTech

Published online 06, September, 2011

Published in print edition September, 2011

This series is directed to diverse managerial professionals who are leading the transformation of individual domains by using expert information and domain knowledge to drive decision support systems (DSSs). The series offers a broad range of subjects addressed in specific areas such as health care, business management, banking, agriculture, environmental improvement, natural resource and spatial management, aviation administration, and hybrid applications of information technology aimed to interdisciplinary issues. This book series is composed of three volumes: Volume 1 consists of general concepts and methodology of DSSs; Volume 2 consists of applications of DSSs in the biomedical domain; Volume 3 consists of hybrid applications of DSSs in multidisciplinary domains. The book is shaped decision support strategies in the new infrastructure that assists the readers in full use of the creative technology to manipulate input data and to transform information into useful decisions for decision makers.

\title{
How to reference
}

In order to correctly reference this scholarly work, feel free to copy and paste the following:

Peng Zhang, Shi-Wei Zhao, Bin Tan, Li-Ming Yu and Ke-Qiang Hua (2011). Applications of Decision Support System in Aviation Maintenance, Efficient Decision Support Systems - Practice and Challenges in Multidisciplinary Domains, Prof. Chiang Jao (Ed.), ISBN: 978-953-307-441-2, InTech, Available from: http://www.intechopen.com/books/efficient-decision-support-systems-practice-and-challenges-inmultidisciplinary-domains/applications-of-decision-support-system-in-aviation-maintenance

\section{INTECH}

open science | open minds

\section{InTech Europe}

University Campus STeP Ri

Slavka Krautzeka 83/A

51000 Rijeka, Croatia

Phone: +385 (51) 770447

Fax: +385 (51) 686166

www.intechopen.com

\section{InTech China}

Unit 405, Office Block, Hotel Equatorial Shanghai

No.65, Yan An Road (West), Shanghai, 200040, China

中国上海市延安西路65号上海国际贵都大饭店办公楼405单元

Phone: +86-21-62489820

Fax: $+86-21-62489821$ 
(C) 2011 The Author(s). Licensee IntechOpen. This chapter is distributed under the terms of the Creative Commons Attribution-NonCommercialShareAlike-3.0 License, which permits use, distribution and reproduction for non-commercial purposes, provided the original is properly cited and derivative works building on this content are distributed under the same license. 